\title{
Personalized Therapy in Breast Cancer
}

\author{
Frederik Marmé Andreas Schneeweiss \\ Department of Gynaecology and Obstetrics, National Center for Tumour Diseases, University of Heidelberg, Germany
}

\section{Keywords}

Personalized therapy - Beast cancer - Intrinsic molecular subtypes · Multigene signatures · HER2 - Cancer genome projects · Prognostic factors · Predictive factors

\section{Summary}

Systemic treatment of non-metastatic breast cancer is based on endocrine therapy, cytotoxic chemotherapy, and molecular targeted therapy - with the major problems of immense overtreatment of patients who would not relapse without systemic therapy and the failure of treatment in others whose disease still recurs. These deficits can only be overcome by the identification of new and better prognostic and predictive markers. Currently, adjuvant treatment stratification is based on a limited number of established factors, namely locoregional tumour stage, age, grade, expression of hormone receptors, HER2, and Ki-67. Molecular profiling techniques, however, have revolutionized our understanding of breast cancer as a heterogeneous disease. Future results from even more comprehensive genetic analyses as part of the coordinated cancer genome projects will help to develop better treatment stratifications and new therapeutic approaches. Efforts to realize the dream of a personalized treatment for breast cancer will include drug development and intelligent design of trials for increasingly small subgroups of patients with specific host and disease characteristics. This will only be made possible by a strong cooperation between basic researchers and translational scientists, clinicians, as well as academia and industry.

\section{Schüsselwörter}

Personalisierte Therapie - Mammakarzinom ·

Intrinsische molekulare Subtypen - Multigensignaturen • HER2 - Krebsgenom-Projekte · Prognostische Faktoren · Prädiktive Faktoren

\section{Zusammenfassung}

Die medikamentöse Therapie des primären Mammakarzinoms basiert auf der endokrinen Therapie, der zytotoxischen Chemotherapie und molekularen, zielgerichteten Therapien. Hierbei bestehen nach wie vor zwei große Probleme: eine inakzeptable Übertherapie von Patientinnen, die auch ohne adjuvante Systemtherapie keinen Krankheitsrückfall erleiden sowie das Therapieversagen bei Patientinnen, deren Krankheit trotz Therapie wiederkehrt. Diese Missstände können nur durch die Identifikation neuer und besserer prognostischer und prädiktiver Faktoren überwunden werden. Derzeit erfolgt die Therapiestratifizierung anhand einer überschaubaren Zahl etablierter Faktoren, nämlich lokoregionale Tumorausbreitung, Alter, Tumorgrad, Hormonrezeptor- und HER2Expression sowie Ki-67. Molekulare Profile und Signaturen habe jedoch in den letzten Jahren unser Verständnis des Mammakarzinoms als heterogene Erkrankung revolutioniert. In Zukunft werden die Ergebnisse der umfassenden genomischen Charakterisierung der Erkrankung im Rahmen der internationalen Krebsgenom-Projekte (Cancer Genome Projects) helfen, weitere therapeutische Ansätze und Ziele zu definieren und zur Verwirklichung einer maßgeschneiderten, personalisierten Therapie beitragen. Die Bemühungen, den Traum einer personalisierten Therapie zu verwirklichen, schließen die Entwicklung neuer Medikamente auf der Basis biologischer Erkenntnisse sowie das intelligente Studiendesign für immer kleiner werdende Subgruppen mit genau definierten Tumorcharakteristika ein. Dies kann nur durch eine starke Kooperation zwischen Grundlagenwissenschaftlern, translationalen Forschern und Klinikern sowie zwischen akademischer Forschung und Industrie gelingen.

\section{KARGER \\ Fax +497614520714 \\ Information@Karger.de}

www.karger.com (c) 2012 S. Karger GmbH, Freiburs

0378-584X/12/3513-0028\$38.00/0

Accessible online at:

www.karger.com/onk
Prof. Dr. med. Andreas Schneeweiss

National Center for Tumour Diseases

University Hospital

Im Neuenheimer Feld 460, 69120 Heidelberg, Germany

Tel. +49 6221 56-35552, Fax -7920

andreas.schneeweiss@med.uni-heidelberg.de 


\section{Introduction}

Systemic treatment of non-metastatic breast cancer is based on endocrine therapy, cytotoxic chemotherapy, and molecular targeted therapy. In this situation, we are faced with 2 major problems: i) an immense overtreatment of patients who would not relapse even without adjuvant treatment; and ii) the failure of therapy in patients who relapse despite adjuvant treatment. The only way to overcome these problems is the identification of new and better prognostic and predictive markers.

\section{The Need for Reliable Prognostic and Predictive Markers}

A clinically useful prognostic marker will accurately separate patients at high risk from those at a very low risk of recurrence. As prognosis is driven by tumour biology and locoregional stage, most patients with newly diagnosed breast cancer exhibit an intermediate risk profile with either a favourable tumour biology but extensive locoregional spread or vice versa. According to current guidelines, a majority of them will be offered adjuvant chemotherapy despite a 10 -year disease-free survival of more than $70 \%$. The relative risk reduction is $30-50 \%$ depending on menopausal status [1]. The absolute survival benefit in this group is, however, small. Furthermore, therapy-specific predictive factors are urgently needed to minimize treatment failure. For patients with no available effective treatment, new drugs have to be developed on a rational basis. Given the huge amount of targeted drugs currently in preclinical and clinical development, more molecular and biologic knowledge has to be integrated into study designs prospectively. This is of utmost importance because new targeted drugs will only be effective in small subgroups of breast cancer patients defined by specific single markers, marker signatures, or functional characteristics. Personalized treatment of breast cancer started in the 1960s with the identification of the oestrogen receptor (ER) and the introduction of tamoxifen as a first targeted agent in the 1970s, and continued with the success story of trastuzumab in HER2-overexpressing tumours beginning in the 1990s. However, apart from these 2 single predictive markers, therapy stratification today is still rather crude. Therefore, this article will focus on how our understanding of breast cancer biology has evolved and how this knowledge can help us in pursuing the aim of a personalized medicine.

\section{Established Predictive and Prognostic Markers}

Therapy stratification today is based on a short list of prognostic and predictive markers. The relapse risk is driven by tumour biology as well as locoregional stage. To date, there are only 2 established predictive markers, expression of ER and HER2, which predict efficacy of either endocrine or HER2-targeted therapy. Amongst the classical clinicopathologic variables, grading is a further marker reflecting tumour biology. Locoregional stage, e.g. tumour size, axillary lymph node involvement, and lymphovascular invasion, as well as the patient's age also greatly influence prognosis. Based on these factors, it is possible to roughly estimate the 10 -year overall survival and disease-free survival by using computerized algorithms such as Adjuvant! Online (www.adjuvantonline.com). Adjuvant! Online, however, is limited by the fact that neither HER2 status nor proliferation makers such as Ki-67 are considered thus far. For example, it is impossible to sufficiently divide the subgroup of patients with node-negative, ER-positive, G2 tumours into a good prognostic group adequately treated with endocrine therapy alone and patients with sufficient high risk of relapse to justify additional chemotherapy. In fact, this is the group of patients for which reliable prognostic factors are most urgently needed.

The treatment of HER2-positive breast cancer is currently most advanced in terms of personalised breast cancer therapy. Only the identification of HER2 overexpression as a predictive marker allowed the demonstration of a substantial survival benefit for the addition of trastuzumab to adjuvant chemotherapy. Besides the monoclonal antibody trastuzumab, further HER2-targeted drugs - namely tyrosine kinase inhibitors (TKIs) and other monoclonal antibodies - have been developed to overcome treatment resistance against trastuzumab. Lapatinib, a TKI against HER2 and HER1, disrupts the HER2 signalling pathway via inhibition of the intracellular tyrosine kinase activity. Lapatinib is active after trastuzumab failure and can enhance efficacy of trastuzumab alone [2-6]. Further HER2-targeted agents such as pertuzumab or T-DM1 are in advanced clinical development and have also demonstrated efficacy in HER2-positive breast cancer after failure of trastuzumab and when given in combination with trastuzumab, respectively [5-7].

Personalized treatment, however, does not mean to target all mechanisms of resistance in all patients and thereby increasing toxicity, but rather the identification of the right HER2-targeted agent or combination of agents for each individual patient. The prerequisite for achieving this goal is to run comprehensive biomarker programs to elucidate the specific mechanisms of resistance in a given patient. Afterwards, biomarker driven trials are needed to prospectively address these resistance mechanisms with an ever growing list of new targeted agents showing significant activity in trastuzumabresistant tumours such as mTOR inhibitors, PI3K inhibitors, and further HER2-targeted agents. The art of personalized medicine will be to select the right treatment for the right patient at the right time as opposed to the 'one size fits all' concept. In this respect, a further subclassification of HER2positive patients will be necessary. 
Table 1. Surrogate definitions of intrinsic subtypes of breast cancer (modified from [11])

\begin{tabular}{lll}
\hline Intrinsic Subtype & Clinico-pathologic definition & Notes \\
\hline Luminal A & 'Luminal A' & This cut-point for Ki-67 labelling index was established by comparison \\
& ER and/or PgR positive, HER2 negative, & with PAM50 intrinsic subtyping. Local quality control of Ki-67 staining \\
& Ki-67 low $(<14 \%)$ & is important. \\
'Luminal B (HER2 negative)' & Genes indicative of higher proliferation are markers of poor prognosis \\
ER and/or PgR positive, HER2 negative, & in multiple genetic assays. If reliable Ki-67 measurement is not available, \\
& Ki-67 high & some alternative assessment of tumor proliferation, such as grade, \\
& & may be used to distinguish between Luminal A and Luminal B (HER2 \\
& 'Luminal B (HER2 positive)' & Both endocrine and anti-HER2 therapy may be indicated.
\end{tabular}

Erb-B2 overexpression 'HER2 positive (non-luminal)'

ER and/or PgR positive, any Ki-67, HER2

Both endocrine and anti-HER2 therapy may be indicated.

$\begin{array}{ll}\text { Erb-B2 overexpression } & \text { 'HER2 positive (non-luminal)' } \\ & \text { HER2 over-expressed or amplified, } \\ & \text { ER and PgR absent } \\ \text { 'Basal-like' } & \text { 'Triple negative (ductal)' } \\ & \text { ER and PgR absent, HER2 negative }\end{array}$

Approximately $80 \%$ overlap between triple negative and intrinsic basal-like subtype but triple negative also includes some special histological types, such as (typical) medullar and adenoid cystic carcinoma with low risks of distant recurrence. Staining for basal keratins although shown to aid selection of true basal-like tumours, is considered insufficiently reproducible for general use.

ER: Oestrogen receptor; PgR: progesterone receptor.

\section{Gene Signatures and Molecular Subtypes}

Molecular profiling technologies have greatly advanced our understanding of breast cancer as a heterogeneous disease. About 10 years ago, Perou et al. [8] have defined 4 major intrinsic molecular subtypes by microarray-based mRNA expression profiling named luminal A, luminal B, HER2enriched, and basal-like. A further subtype called normal-like breast cancer is now thought to be mainly caused by contamination with normal breast tissue. As these subtypes significantly differ in incidence, survival, and response to therapy [9, 10], the terms luminal A and B, basal-like, etc. have been adopted into clinical practice. However, molecular profiling technologies are not routinely available in clinical practice. Therefore, surrogate definitions for these subtypes have been developed based on 4 classical immunohistological markers, the expression of ER, progesterone receptor (PgR), HER2, and Ki-67 (table 1) [11]. These surrogate definitions have been recommended as the main stratifiers for adjuvant systemic treatment of early breast cancer by the St. Gallen International Expert Consensus on the Primary Therapy of Early Breast Cancer 2011 [11]. This clearly reflects the change in the understanding of the tumour biology of breast cancer over the past decade.

Luminal breast cancers are hormone receptor-positive tumours with the luminal A subtype being comprised of strongly hormone receptor-expressing, slowly proliferating, low-grade tumours, whereas luminal B tumours are hormone receptorpositive tumours with either a higher proliferation rate or overexpression of HER2. Most of the HER2-enriched tumours will be HER2-positive, but there are a number of tumours which would not be classified as HER2-positive by immunohistochemistry (IHC) but show a high expression of the HER2 gene cluster, indicating that they are driven by this pathway. This is due to the fact that these intrinsic subtypes are defined by expression profiles as opposed to single immunohistological markers and that the overlap is not perfect. The basal-like subgroup is mainly comprised of triple-negative tumours (80\%). However, among the triple-negative tumours, only about $75-80 \%$ would be classified as basal-like according to their gene expression profiles [9]. In fact, some of the ER-positive breast cancers will fall into the basal-like group and some ER-negative tumours into the luminal group according to their mRNA expression profiles, and this appears to be reflected in their prognosis [12]. These intrinsic subtypes differ greatly in prognosis, with the luminal A subtype standing out with a highly favourable prognosis. For this subtype, endocrine therapy alone is sufficient, whereas luminal B, HER2-enriched, and basal-like tumours have a distinctly poorer prognosis which warrants chemotherapy. In addition, response to chemotherapy differs between those intrinsic subgroups. Luminal A tumours hardly ever achieve a pathological complete response ( $\mathrm{pCR}$ ) following neoadjuvant chemotherapy whereas pCR rates for luminal B, HER2-enriched, and basal-like subtypes amount to 18,41 , and 59\%, respectively $[10,13]$. The achievement of pCR is accepted as one of the strongest prognostic factors following the neoadjuvant setting, at least for HER2-positive and triple-negative breast cancer [14]. It must be noted that these surrogate definitions inevitably miss some information of the mRNA profile-based subtypes, but due to their general availability they are clinically useful. 


\section{Ongoing Efforts of Further Subclassification}

Recently, a new intrinsic subtype, called 'claudin-low', has bee described. This subtype shares several gene expression features with basal-like breast cancer but distinctly exhibits mesenchymal and stem cell-like features. The low expression of cell-cell adhesion molecules, including 3 claudin genes has led to its name. Clinically, this subtype mostly consists of triple-negative tumours, frequently with metaplastic and medullary differentiation, and has a poor prognosis. The proliferation gene cluster expression is distinctly lower than that of the basal-like subtype but higher compared to luminal A tumours. Response to standard neoadjuvant chemotherapy ranges between the basal-like and luminal B breast cancer subtypes.

In addition, further subclassification will help to identify new important targets in small subgroups of patients. As an example, Doane et al. [15] discovered a subset of ER-negative breast cancers by mRNA expression profiling, which show a transcriptional program regulated by androgens. The overexpression of androgen receptor (AR) in combination with an AR-regulated gene expression profile make this a potential therapeutic target. This has already led to the evaluation of the AR antagonist bicalutamide in metastatic breast cancer within a phase II trial. It is expected that 180 hormone receptor-negative patients will have to be screened for AR expression in order to include 28 into the trial. This reflects one of the biggest obstacles for a truly personalized approach to breast cancer therapy: the implementation of trials with targeted therapies in very small subgroups defined by the expression of the target of interest. On the other hand, by selecting a clearly defined very small subset of patients, trial results will not be diluted by the inclusion of an off-target population.

\section{Prognostic Multigene Assays}

Distinct molecular profiling approaches have directly aimed at dividing patients into those with a good prognosis and those with a poor prognosis in order to minimize overtreatment of patients at low risk of recurrence. These efforts have led to a number of prognostic multigene assays. The most prominent examples are the Recurrence Score (RS), the Amsterdam Signature (AS), and the Genomic Grade Index (GGI). To date, there are no prospective data from randomized trials to validate any of these signatures, yet the first two are currently being evaluated in large prospective randomized trials.

$\mathrm{RS}$ is based on reverse transcription polymerase chain reaction (RT-PCR) analysis of a panel of 21 genes, 5 housekeeping genes and 16 cancer-related genes reflecting characteristics such as proliferation, hormone responsiveness, HER2 signalling, invasiveness and apoptosis. The mRNA level of the 4 most important immunohistological markers ER, PgR, HER2, and Ki-67 are included in this panel, leaving 12 additional cancer-related genes which are unique. Applying a mathematical algorithm to the individual expression measurements results in an RS ranging from 0 to 100, which strongly correlates with prognosis according to a retrospective analysis of a node-negative, ER-positive breast cancer population treated with tamoxifen only within the NSABP-B14 [16]. RS has been retrospectively validated in 4 patient cohorts derived from large randomized clinical trials (NSABP B14, B20, ATAC, and SWOG8814), with consistent results [17-19]. Overall, about $50 \%$ of patients are grouped into the low-risk category $(\mathrm{RS}<18)$ and approximately $25 \%$ into each the intermediate (RS 18-30) and the high-risk group (RS > 30). Retrospective analysis of trials comparing endocrine versus chemoendocrine adjuvant treatment shows a substantial benefit of chemotherapy only for the high-risk group. The benefit for the intermediate group seems limited but a definite answer warrants validation in a prospective trial. This is currently being addressed by the TAILORX trial. Patients $(\mathrm{ER}+, \mathrm{N} 0)$ with an intermediate $\mathrm{RS}$ will be randomized to either chemotherapy + endocrine treatment or to endocrine treatment alone. The cut-offs for the intermediate risk group have been adjusted for this trial (RS 11-25). However, even if this trial is positive, the most important question still remains whether this multigene assay performs significantly better than an algorithm based on modern, quality-controlled pathology including ER, PgR, HER2, Ki-67 and TNM stage, as well as grade. A recent report on the ATAC trial cohort directly comparing an IHC-based model with RS challenged this hypothesis by demonstrating that the IHC model was not inferior to RS in predicting prognosis [20]. One of the advantages of a centralized test is the rigorous quality control and robustness, which is further enhanced by measuring gene sets rather than individual genes. The integration of locoregional stage and RS has refined the distant recurrence risk assessment and reduced the number of patients classified as intermediate risk, but has not enhanced the ability to predict chemotherapy benefit [21].

The AS is composed of a set of 70 genes and divides patients into a 'good' and 'poor' prognostic group. It has also been retrospectively validated in several studies with consistent results [22-29]. In contrast to RS, this test requires fresh tumour tissue. Comparison to classical histopathologic criteria using Adjuvant! Online showed a discordance rate of $30 \%$ and a superior risk stratification for AS. Currently, AS is being evaluated in the large randomized MINDACT trial which randomizes patients who have a discordant risk according to clinicopathologic assessment and AS in terms of systemic treatment and risk of relapse either predicted by established clinicopathologic features or AS.

The GGI has been designed to segregate histopathologic grade 2 tumours into molecular grade 1 or 3 [30]. Numerous further multigene prognostic signatures have been developed in retrospective analyses, which despite of a lack of great overlap between the tested genes all seem to measure similar pathways based on a metagene rather than single gene level. 


\section{The Cancer Genome Project}

A further dimension of insight into the biology and diversity of breast cancer (and other tumours) can hopefully be expected from the results of the network of cancer genome projects coordinated by the International Cancer Genome Consortium [31]. These projects aim to generate a comprehensive catalogue of genomic abnormalities conferring oncogenic properties using state-of-the-art high-throughput genome analysis techniques. These network projects are unique in terms of size of the analysed patient cohorts as well as the number of different techniques used to comprehensively characterize genomic alterations. Apart from the sequencing of the cancer genomes and matched germline DNA to define driver and passenger mutations within the 50 most relevant tumour types and subtypes currently included, these projects include gene expression profiling, copy number variation profiling, SNP genotyping, genome-wide DNA methylation profiling, and microRNA profiling. Regarding breast cancer, the cancer genome project has been organized in subprojects concentrating on specific subtypes, e.g. ER+, HER2-, HER2+, and triple-negative disease, in order to develop new specific therapeutic strategies.

First results have been recently published on high-grade serous ovarian cancer [32]. In high-grade serous ovarian cancer, $51 \%$ of cases were found to have defects in the homologous recombination repair pathway to name just one prominent pathway. These included 12 different alterations affecting 9 different genes ranging from germline and somatic mutations, promoter methylation to deletions, and altered expression. Such alterations might make these patients ideal candidates for PARP inhibitor therapy which has efficacy, based on synthetic lethality, restricted to tumours with insufficient homologous recombination. A recent randomized trial with olaparib, an oral PARP inhibitor, as maintenance therapy after platinum-based chemotherapy demonstrated a substantial activity in patients with high-grade serous ovarian cancer. It will be interesting to see whether similar alterations within the homologous recombination repair pathway can be observed in breast cancer as a predictive factor for PARP inhibitor activity in this subgroup.

\section{Hypothesis-Driven Approaches}

Apart from such screening approaches, approaches driven by a biologic hypothesis are very promising to help better treatment stratification. Recently, colleagues from the Netherlands Cancer Institute (NKI) in Amsterdam have defined an array comparative genomic hybridisation (aCGH) BRCAness classifier by detecting common aCGH signatures for BRCA1and BRCA2-mutated tumours. Interestingly, these BRCA- ness classifier signatures can also be detected in $30 \%$ of patients with sporadic breast cancer and are predictive for superior survival after high-dose chemotherapy with autologous stem cell transplantation, including high doses of alkylating agents and platinum salts, which allegedly are highly active in BRCA mutation carriers. Today, there is no role for highdose chemotherapy in breast cancer, but these BRCAness classifier might be able to predict response to PARP inhibitor therapy in patients beyond BRCA mutation carriers. Thus far, other stratification strategies, e.g. based on a triple-negative phenotype, have failed, and a good predictor for this class of drug is eagerly awaited. Within the framework of this article, many important aspects, such as the role of circulating tumour cells and their phenotypic characterization on the single-cell level, have been omitted; still these as well as pharmacogenetic aspects, i.e. the prediction of dose-limiting toxicities, efficacy, and drug metabolism on the basis of genetic germline polymorphisms, have the potential to play an important role in personalized treatment of breast cancer.

\section{Conclusions}

Based on the evolving data from comprehensive genomic characterization of breast cancer in the ongoing projects, as well as triggered by hypotheses generated in preclinical models, specific subgroups of patients have to be defined early on during drug development on the basis of biomarkers and functional assays included in clinical trials. The neoadjuvant setting is the ideal strategy to advance breast cancer therapy towards personalized medicine. Neoadjuvant therapy allows for an in vivo sensitivity testing, makes sequential biopsies feasible, and offers the opportunity to test if a certain drug actually hits its target by analysing molecular changes within the tumour tissue before and after a certain time of treatment. By including windows of treatment with one drug of interest, it is also possible to selectively study effects of one specific treatment and test. This way, biological hypotheses defined in preclinical models or integrative analyses of genomic alterations can be validated in a short period of time with direct response measurements and analysis of molecular changes within the tumour by serial biopsies or at the time of surgery. As the achievement of a pCR is a surrogate for an excellent prognosis, this endpoint can help to decide very early around the time of surgery which treatment strategy should be carried over into large randomized adjuvant trials.

\section{Disclosure Statement}

The authors did not provide a conflict of interest statement. 


\section{References}

1 Peto R; for the Early Breast Cancer Trialists' Collaborative Group: The worldwide overview: new results for systemic adjuvant therapies. Presentation at the 30th Annual SABCS, San Antonio, TX, USA, Dec 13-16, 2007.

2 Guarneri V, Frassoldati A, Bottini A, Generali DG, Cagossi K, et al.: Final results of a phase II randomized trial of neoadjuvant anthracycline-taxane chemotherapy plus lapatinib, trastuzumab, or both in HER2-positive breast cancer (CHER-LOB trial). ASCO Ann Meet Proc 2011. J Clin Oncol 2011;29(suppl):abstr 507.

3 Blackwell KL, Burstein HJ, Storniolo AM, Rugo H, Sledge G, Koehler M, Ellis C, Casey M, Vukelja S, Bischoff J, Baselga J, O'Shaughnessy J: Randomized study of lapatinib alone or in combination with trastuzumab in women with ErbB2positive, trastuzumab-refractory metastatic breast cancer. J Clin Oncol 2010;28:1124-30.

4 Chang JCN, Mayer IA, Forero-Torres A, Nanda R, Goetz MP, et al.: TBCRC 006: a multicenter phase II study of neoadjuvant lapatinib and trastuzumab in patients with HER2-overexpressing breast cancer. ASCO Ann Meet Proc 2011. J Clin Oncol 2011;29(suppl):abstr 505.

5 Gianni L, Pienkowski T, Im YH, Roman L, Tseng L-M, Liu M-C, Lluch-Hernandez A, Semiglazov V, Szado T, Ross G: Neoadjuvant pertuzumab $(\mathrm{P})$ and trastuzumab $(\mathrm{H})$ : antitumor and safety analysis of a randomized phase II study ('NeoSphere'). 33rd Annual CTRC-AACR SABCS, San Antonio, TX, USA, Dec 8-12, 2010; Cancer Research 2010;70:abstr S3-2.

6 Baselga J, Bradbury I, Eidtmann H, Di Cosimo S, Aura C, De Azambuja E, Gomez H, Dinh P, Fauria K, Van Dooren V, Paoletti P, Goldhirsch A, Chang T-W, Lang I, Untch M, Gelber RD, PiccartGebhart M; on Behalf of the NeoALTTO Study Team: First results of the NeoALTTO trial (BIG 01-06 / EGF 106903): a phase III, randomized, open label, neoadjuvant study of lapatinib, trastuzumab, and their combination plus paclitaxel in women with HER2-positive primary breast cancer. 33rd Annual CTRC-AACR SABCS, San Antonio, TX, USA, Dec 8-12, 2010; Cancer Research 2010; 70:abstr S3.

7 Hurvitz S, Dirix L, Kocsis J, Gianni L, Lu J, Vinholes J, Song C, Tong B, Chu YW, Perez EA Trastuzumab emtansine (T-DM1) vs. trastuzumab plus docetaxel $(\mathrm{H}+\mathrm{T})$ in previously-untreated HER2-positive metastatic breast cancer (MBC): primary results of a randomized, multicenter, open-label phase II study (TDM4450g/BO21976). Eur J Cancer 2011;47:S330.

$\checkmark 8$ Perou CM, Sorlie T, Eisen MB, van de Rijn M, Jeffrey SS, Rees CA, Pollack JR, Ross DT, Johnsen H, Akslen LA, Fluge O, Pergamenschikov A, et al.: Molecular portraits of human breast tumours. Nature 2000;406:747-52.

$\checkmark 9$ Prat A, Perou CM: Deconstructing the molecular portraits of breast cancer. Mol Oncol 2011;5:5-23.

10 Parker JS, Mullins M, Cheang MC, Leung S, Voduc D, Vickery T, Davies S, Fauron C, He X, Hu Z, Quackenbush JF, Stijleman IJ, et al.: Supervised risk predictor of breast cancer based on intrinsic subtypes. J Clin Oncol 2009;27:1160-7.
11 Goldhirsch A, Wood WC, Coates AS, Gelber RD, Thurlimann B, Senn HJ: Strategies for subtypes dealing with the diversity of breast cancer: highlights of the St Gallen International Expert Consensus on the Primary Therapy of Early Breast Cancer 2011. Ann Oncol 2011;22:1736-47.

12 Parker JS, Mullins M, Cheang MC, Leung S, Voduc D, Vickery T, Davies S, Fauron C, He X, Hu Z, Quackenbush JF, Stijleman IJ, et al.: Supervised risk predictor of breast cancer based on intrinsic subtypes. J Clin Oncol 2009;27:1160-7.

13 Parker J: A supervised risk predictor of breast cancer based on biological subtypes. ASCO Ann Meet Proc 2008. J Clin Oncol 2008;26(suppl):abstr 11008.

14 Von Minckwitz G, Kaufmann M, Kuemmel S, Fasching PA, Eiermann W, et al.: Correlation of various pathologic complete response (pCR) definitions with long-term outcome and the prognostic value of pCR in various breast cancer subtypes: results from the German neoadjuvant meta-analysis. ASCO Ann Meet Proc 2011. J Clin Oncol 2011; 29(suppl):abstr 1028.

15 Doane AS, Danso M, Lal P, Donaton M, Zhang L, Hudis C, Gerald WL: An estrogen receptor-negative breast cancer subset characterized by a hormonally regulated transcriptional program and response to androgen. Oncogene 2006;25:3994-4008.

16 Paik S, Shak S, Tang G, Kim C, Baker J, Cronin M, Baehner FL, Walker MG, Watson D, Park T, Hiller W, Fisher ER, et al.: A multigene assay to predict recurrence of tamoxifen-treated, nodenegative breast cancer. N Engl J Med 2004;351: 2817-26.

17 Albain KS, Paik S, van't Veer L: Prediction of adjuvant chemotherapy benefit in endocrine responsive, early breast cancer using multigene assays. Breast 2009;18(suppl 3):S141-5.

18 Paik S, Tang G, Shak S, Kim C, Baker J, Kim W, Cronin M, Baehner FL, Watson D, Bryant J, Costantino JP, Geyer CE Jr, et al.: Gene expression and benefit of chemotherapy in women with node-negative, estrogen receptor-positive breast cancer. J Clin Oncol 2006;24:3726-34.

19 Dowsett M, Cuzick J, Wale C, Forbes J, Mallon EA, Salter J, Quinn E, Dunbier A, Baum M, Buzdar A, Howell A, Bugarini R, et al.: Prediction of risk of distant recurrence using the 21-gene recurrence score in node-negative and node-positive postmenopausal patients with breast cancer treated with anastrozole or tamoxifen: a TransATAC study. J Clin Oncol 2010;28:1829-34.

20 Cuzick J, Dowsett M, Pineda S, Wale C, Salter J, Quinn E, Zabaglo L, Mallon E, Green AR, Ellis IO, Howell A, Buzdar AU, et al.: Prognostic value of a combined estrogen receptor, progesterone receptor, Ki-67, and human epidermal growth factor receptor 2 immunohistochemical score and comparison with the genomic health recurrence score in early breast cancer. J Clin Oncol 2011;29:4273-8.

21 Tang G, Shak S, Paik S, Anderson SJ, Costantino JP, Geyer CE Jr, Mamounas EP, Wickerham DL, Wolmark N: Comparison of the prognostic and predictive utilities of the 21-gene Recurrence Score assay and Adjuvant! for women with node-negative, ER-positive breast cancer: results from NSABP B-14 and NSABP B-20. Breast cancer Res Treat 2011;127:133-42.
22 Bueno-de-Mesquita JM, Sonke GS, van de Vijver MJ, Linn SC: Additional value and potential use of the 70-gene prognosis signature in nodenegative breast cancer in daily clinical practice. Ann Oncol 2009;22:2021-30.

23 Bueno-de-Mesquita JM, van Harten WH, Retel VP, van't Veer LJ, van Dam FS, Karsenberg K, Douma KF, van Tinteren H, Peterse JL, Wesseling J, Wu TS, Atsma D, et al.: Use of 70-gene signature to predict prognosis of patients with node-negative breast cancer: a prospective community-based feasibility study (RASTER). Lancet Oncol 2007; 8:1079-87.

24 Buyse M, Loi S, van't Veer L, Viale G, Delorenzi M, Glas AM, d'Assignies MS, Bergh J, Lidereau R, Ellis P, Harris A, Bogaerts J, et al.: Validation and clinical utility of a 70-gene prognostic signature for women with node-negative breast cancer. J Natl Cancer Inst 2006;98:1183-92.

25 Knauer M, Mook S, Rutgers EJ, Bender RA, Hauptmann M, van de Vijver MJ, Koornstra RH, Bueno-de-Mesquita JM, Linn SC, van't Veer LJ: The predictive value of the 70-gene signature for adjuvant chemotherapy in early breast cancer. Breast Cancer Res Treat 2010;120:655-61.

26 Mook S, Schmidt MK, Weigelt B, Kreike B, Eekhout I, van de Vijver MJ, Glas AM, Floore A, Rutgers EJ, van't Veer LJ. The 70-gene prognosis signature predicts early metastasis in breast cancer patients between 55 and 70 years of age. Ann Oncol 2010;21:717-22.

27 Straver ME, Glas AM, Hannemann J, Wesseling J, van de Vijver MJ, Rutgers EJ, Vrancken Peeters MJ, van Tinteren H, van't Veer LJ, Rodenhuis S: The 70-gene signature as a response predictor for neoadjuvant chemotherapy in breast cancer. Breast Cancer Res Treat 2010;119:551-8.

28 Van't Veer LJ, Dai H, van de Vijver MJ, He YD, Hart AA, Mao M, Peterse HL, van der Kooy K, Marton MJ, Witteveen AT, Schreiber GJ, Kerkhoven RM, et al.: Gene expression profiling predicts clinical outcome of breast cancer. Nature 2002;415:530-6.

29 Van de Vijver MJ, He YD, van't Veer LJ, Dai H, Hart AA, Voskuil DW, Schreiber GJ, Peterse JL, Roberts C, Marton MJ, Parrish M, Atsma D, et al.: A gene-expression signature as a predictor of survival in breast cancer. N Engl J Med 2002; 347:1999-2009.

30 Loi S, Haibe-Kains B, Desmedt C, Lallemand F, Tutt AM, Gillet C, Ellis P, Harris A, Bergh J, Foekens JA, Klijn JG, Larsimont D, et al.: Definition of clinically distinct molecular subtypes in estrogen receptor-positive breast carcinomas through genomic grade. J Clin Oncol 2007;25:1239-46.

31 Hudson TJ, Anderson W, Artez A, Barker AD, Bell C, Bernabe RR, Bhan MK, Calvo F, Eerola I, Gerhard DS, Guttmacher A, Guyer M, et al.: International network of cancer genome projects. Nature 2010;464:993-8.

32 Network TCGA: Integrated genomic analyses of ovarian carcinoma. Nature 2011;474:609-15. 